\title{
Numerical Simulation of Fluid Flow and Heat Transfer of the Supercritical Water in Different Fuel Rod Channels
}

\author{
Huirui Han, Chao Zhang \\ Mechanical \& Materials Engineering \\ Western University \\ London, Canada \\ czhang@eng.uwo.ca
}

\begin{abstract}
The supercritical water-cooled reactor was proposed as one of the Generation IV nuclear systems. Although many research works on the fluid flow and heat transfer of supercritical water in circular channels have been conducted, there is still lack of research on the fluid flow and heat transfer process in fuel bundles used in supercritical water-cooled nuclear reactors. Besides, fuel bundles have multiple fuel rods, the flow is an external flow, not internal flow as that in circle channels, which will cause the difference in the fluid flow phenomenon and heat transfer on the fuel rod cladding surface. In this work, the heat transfer and fluid flow characteristics of the supercritical water in the single-rod channel and the multi-rod channel are simulated numerically. The results show that there are secondary flows in both channels. The circumferential cladding surface temperature variation is large and should be considered in the future fuel rod design. With the same flow rate and heat flux input, the maximum cladding surface temperature in the multi-rod channel is much higher than that in the single-rod channel. Since the maximum cladding surface temperature is an important parameter for the safety of the nuclear reactor operation, it is recommended to use the multi-rod channel model to conduct numerical simulations for the fluid flow and heat transfer of the supercritical water in the Canadian SCWR.
\end{abstract}

Keywords- SCWR, heat transfer, single-rod, multi-rod, cladding surface temperature

\section{INTRODUCTION}

With the rapid growing population, the electricity generation amount is in high demand. Nuclear reactor power plants can provide higher power-to-sources rate, compared with thermal power plants using coals or natural gas. Canada has a long history in the development of the CANada Deuterium Uranium Pressurized Heavy Water Reactor (CANDU-PHWR), which has been operating for about half century. The Supercritical Water-Cooled Reactor (SCWR) is proposed as one of the six selected Generation IV reactor systems in the world since 2002 [1], which has unique advantages, such as higher thermal efficiency, lower coolant mass flow to the thermal power rate, and simpler components.

The studies for the flow in rod bundles have been conducted by several researchers. Kjellstrom [2] did the flow profile measurements of air flows in a triangular rod bundle. Trupp and Azad [3] changed the pitch-to-diameter ratios of hexagonal lattices between 1.2 and 1.5 and measured detailed turbulence profiles of the air flow. The eddy viscosity showed strong anisotropy. Carajilescov and Todreas [4] and Vonka [5] used Laser Doppler Anemometry to measure the water flow characteristics in triangular subchannels. They found that the secondary flow velocity was less than $1 \%$ of the mean flow velocity.

Many researchers have investigated the turbulent mixing rate of the fluids in channels. Jeong et al. [6] defined a new mixing factor and then evaluated all the experimental data from previous researchers on the turbulent mixing. It was found that the turbulent mixing of fluids depends strongly on the ratio of the distance between the center of two adjacent sub-channels and the hydraulic diameter of a sub-channel. Only very few experimental studies were carried out for the heat transfer and flow phenomenon of supercritical fluids because of the experiment environment restrictions. $\mathrm{Xi}$ et al. [7] did an investigation on the supercritical water flow between two heated parallel channels. Both inlet mass flow rate and outlet temperature oscillations were observed. Verma et al. [8] carried out the experiments using a scaled test facility of AHWR (Advanced Heavy Water Reactor) rod bundle. The effect of the spacer on the turbulent mixing rate in subchannels was investigated. The results showed that the turbulent mixing rate increased with the increase in the average Reynolds number.

The simulation results for the flow of the supercritical water in fuel bundles showed that the anisotropic turbulence models are more accurate. $\mathrm{Gu}$ et al. [9] simulated the supercritical water flow in a SCWR fuel bundle using the sub-channel method. The simulation results demonstrated that the turbulent mixing rate was sensitive to the asymmetric boundary condition. Mukohara et al. [10] conducted the sub-channel analysis in High Temperature Fast Supercritical Water-cooled Reactor (HTF-SCWR). It was found that the cladding surface 
temperature was sensitive to both the local power peak value and the sub-channel area. Yu et al. [11] developed a subchannel analysis code to analyze the thermo-hydraulic behavior of the CANDU-SCWR. The simulation results showed that this code can successfully simulate the steady state flows in subchannels.

The Canadian SCWR concept is based on CANDU. Because of the sharp variation of the supercritical water properties around the pseudo-critical point, it is important to use appropriate anisotropic turbulence models for the simulations of the supercritical water flow behaviors and heat transfer phenomenon in fuel bundles. Previous researchers Cheng et al. [12] and Zhang et al. [13] have proved that the anisotropic model RSM (Reynolds Stress Model) can give a better agreement with the experimental results for the supercritical water flow in channels compared with the isotropic two-equation turbulence models.

Previous numerical studies mainly focused on the flow and heat transfer phenomenon of the supercritical water in circle channels. However, the fuel bundle used in the SCWR has multiple fuel rods. It is time-consuming to simulate the fluid flow and heat transfer in the channel with multiple rods. Therefore, some researchers conducted simulations using simplified geometries, such as the work by Sun et al. [14], where the multiple fuel rod system was simplified as a singlerod system. Therefore, in this study, the CFD (Computational Fluid Dynamics) simulations are carried out for the fluid flow and heat transfer of the supercritical water in both the singlerod channel and multi-rod channel under the same operating conditions in order to compare the difference in the results between them. The CFD simulations are conducted with the RSM using ANSYS FLUENT 15.0.

\section{GOVERNING EQUATIONS AND NUMERICAL MODELS}

The governing equations for 3D steady flow and heat transfer are conservations of mass equation, momentum equation and energy equation, which is shown as follows in the Cartesian tensor [15]:

$$
\begin{gathered}
\frac{\partial}{\partial x_{i}}\left(\rho \overline{u_{i}}\right)=0 \\
\frac{\partial}{\partial x_{j}}\left(\rho \overline{u_{i} u_{j}}\right)=-\frac{\partial \bar{p}}{\partial x_{i}}+\frac{\partial}{\partial x_{j}}\left(\mu \frac{\partial u_{i}}{\partial x_{j}}-\rho_{u_{i} u_{j}}\right)+\rho g_{i} \\
\frac{\partial}{\partial x_{i}}\left(\overline{u_{i}} \rho_{c_{p}} T\right)=\frac{\partial}{\partial x_{i}}\left[\left(\lambda+\frac{c_{p} \mu_{t}}{P_{r_{t}}}\right) \frac{\partial T}{\partial x_{i}}\right]+\phi
\end{gathered}
$$

Here, $u$ is the velocity, $\mathrm{T}$ is the temperature, $\mu$ is the dynamic viscosity, $\rho$ is the density, $\lambda$ is the thermal conductivity, $c_{p}$ is the specific heat, $\mu_{t}$ is the turbulent viscosity, and $P_{r_{t}}$ is the turbulent Prandtl number. The RSM with the enhanced wall treatment is chosen in this study based on the recommendations from the previous studies [13]. ANSYS Fluent 15.0 is used to solve the governing equations. The SIMPLE scheme is selected for pressure correction, and QUICK method is used for the spatial discretization. The convergence criteria for continuum is $10^{-3}$, for the momentum and turbulence parameters are $10^{-5}$, and for the energy equations is $10^{-6}$.

\section{CONFIGURATIONS OF THE CHANNELS}

The cross-section views of the single-rod channel and the multi-rod channel are shown in Fig. 1 and Fig. 2, respectively. The working fluid is the supercritical water, and its properties are from Wagner [16]. The length of the channel is $1.5 \mathrm{~m}$. For the single-rod channel, the channel diameter is $9 \mathrm{~mm}$ and the rod diameter is $4 \mathrm{~mm}$. And for the multi-rod channel, the outer diameter is $9 \mathrm{~mm}$. There are 5 rods in the channel and their diameter is $1.788 \mathrm{~mm}$, so, the total cross-section areas of all 5 rods is equal to the cross-section area of the rod in the singlerod channel. The supercritical water flow in these channels is upward based on the configuration of the proposed SCWR [17]. The reference pressure is $25 \mathrm{MPa}$ [17].

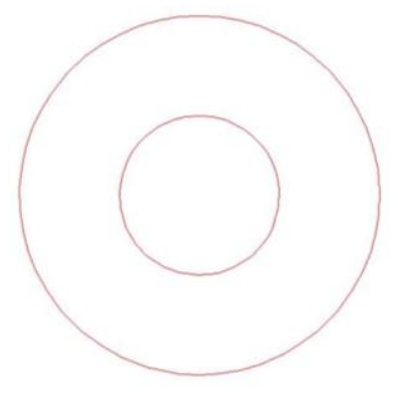

Figure 1. Cross-section view of the single-rod channel

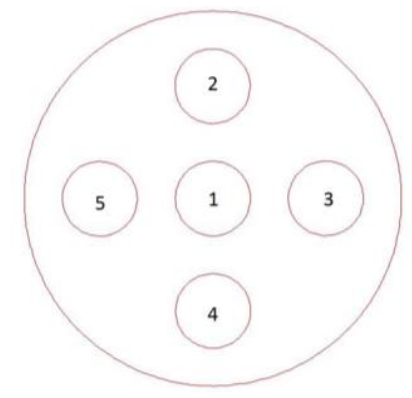

Figure 2. Cross-section view of the single-rod channel

Boundary conditions are as follows:

Inlet: The inlet velocity for each channel is $3 \mathrm{~m} / \mathrm{s}$, and the inlet temperature is $623.15 \mathrm{~K}$. Turbulence intensity is set as $5 \%$, and the hydraulic diameters are specified based on the geometrical shapes of the channels.

Outlet: Outflow is selected for each channel.

Walls: They are all smooth walls with the no-slip condition. The heat flux on the fuel rod surface is $10^{6} \mathrm{~W} / \mathrm{m}^{\wedge} 2$ based on the operating condition of the SCWR [17].

The cross-section views of the meshes for these two channels are shown in Fig. 3 and Fig. 4, respectively. The 
mesh refinement near the wall is performed so that the nondimensional distance to the wall is approximately 1 .

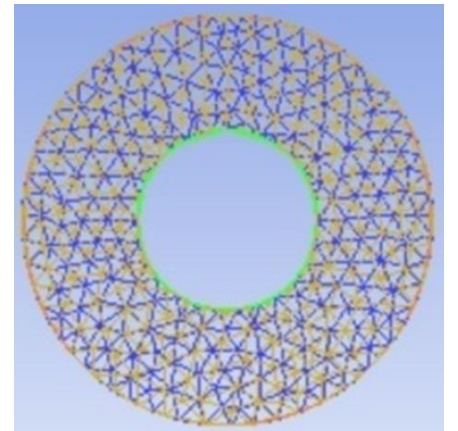

Figure 3. Cross-section view of the mesh for the single-rod channel

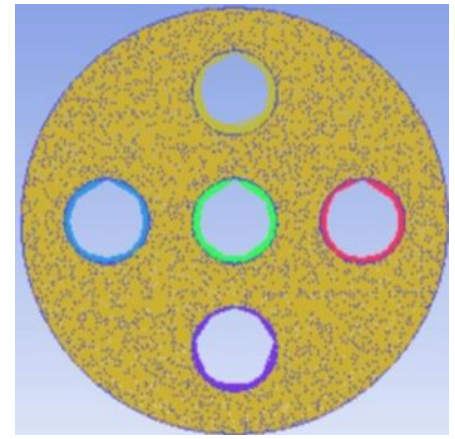

Figure 4. Cross-section view of the mesh for the single-rod channel

\section{RESULTS AND DisCUSSIONS}

Fig. 5 shows the outlet velocity vectors colored by the velocity magnitude of the supercritical water in the single-rod channel and the multi-rod channel. It is shown that there are secondary flows at the outlet plane in the single-rod channel and the multi-rod channel, especially near the fuel rod cladding surfaces. Fig. 6 shows the contours of the outlet velocity magnitudes in the single-rod channel and multi-rod channel. The velocity magnitudes at the outlets of these two channels are quite different. The velocity magnitude in the single-rod channel is much lower than that in the multi-rod channel. The maximum velocity at the outlet is $4.5 \mathrm{~m} / \mathrm{s}$ in the single-rod channel and $7 \mathrm{~m} / \mathrm{s}$ in the multi-rod channel. The velocity field will affect the heat transfer in the channel. Therefore, using a single-rod channel to replace the multi-rod channel used in the Canadian SCWR will cause inaccurate results.

The cladding surface temperature distribution in the singlerod channel is shown in Fig. 7. The difference in the cladding surface temperature along the circumference in the single-rod channel is less than 50K. Fig. 8 shows the cladding surface temperature distribution in the multi-rod channel. It can be seen that the cladding surface temperature difference along the circumference in the multi-rod channel can reach to about $150 \mathrm{~K}$.

Fig. 9 to Fig. 11 show the maximum and minimum cladding surface temperatures of each fuel $\operatorname{rod}$ at $\mathrm{z}=0.1 \mathrm{~m}$, $\mathrm{z}=0.8 \mathrm{~m}$, and $\mathrm{z}=1.5 \mathrm{~m}$ in the multi-rod channel. It can be seen that the maximum cladding surface temperature at these three planes all occur at the fuel rod \#4. And the minimum cladding surface temperature at these three planes occur at the fuel rods \#1, \#5, \#5, respectively. The largest difference of maximum and minimum cladding surface temperatures occurs at the fuel rod\#4 at the outlet plane $\mathrm{z}=1.5 \mathrm{~m}$, which is $78.537 \mathrm{~K}$. The maximum cladding surface temperature is $670 \mathrm{~K}$ for the singlerod channel and $780 \mathrm{~K}$ for the multi-rod channel. The difference is $110 \mathrm{~K}$. Therefore, the multi-channel model should be used in the simulation to generate more accurate data used for the control system designs since the maximum cladding surface temperature is an important parameter for the safety of nuclear reactors.
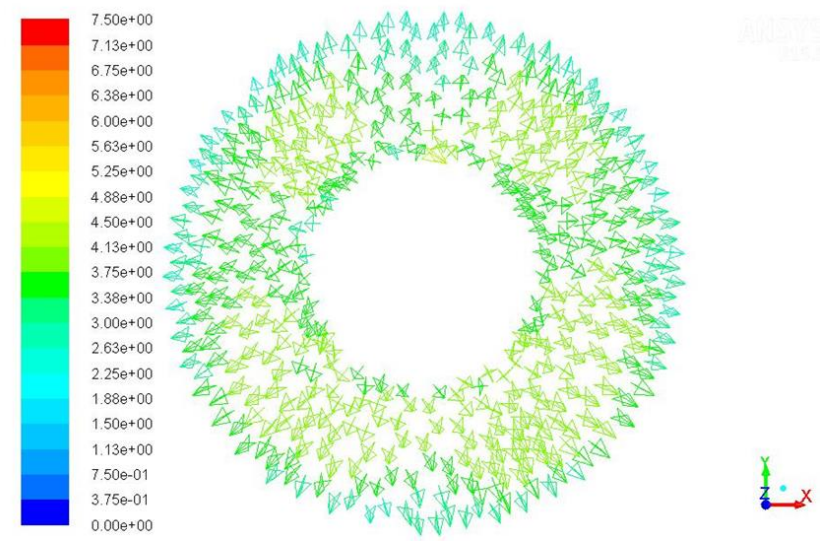

(a) Single-rod Channel
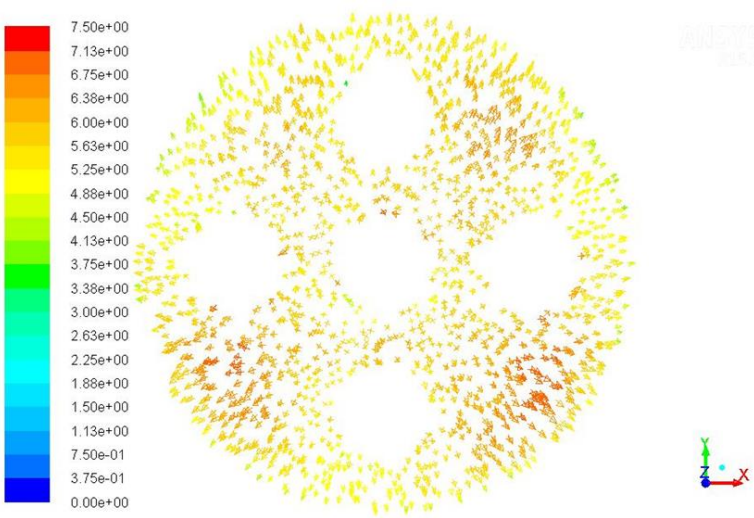

(b) Multi-rod Channel

Figure 5 . Outlet velocity vectors colored by the velocity magnitude $(\mathrm{m} / \mathrm{s})$ in the single-rod and multi-rod channels
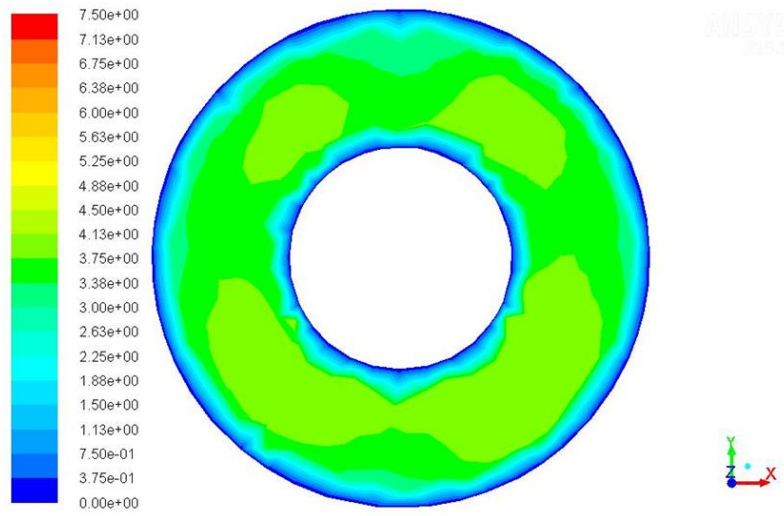

(a) Single-rod channel 


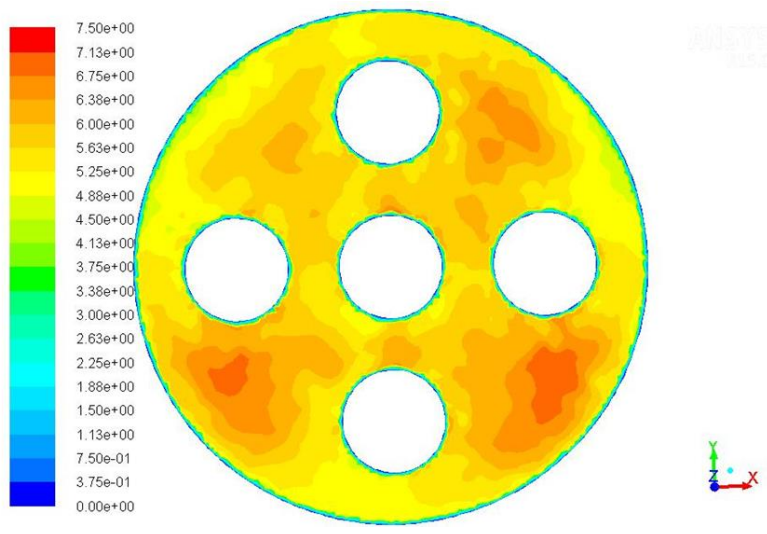

(b) Multi-rod channel

Figure 6 Outlet velocity magnitude $(\mathrm{m} / \mathrm{s})$ contours in the single-rod and multirod channels
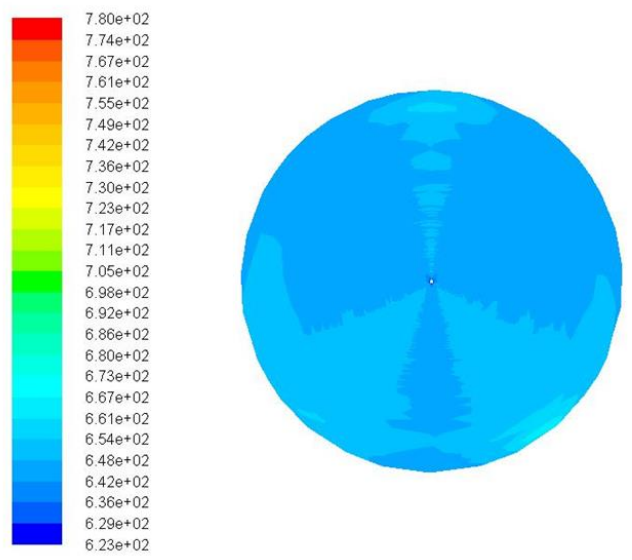

$29 \mathrm{e}+02$

$23 e+02$

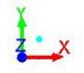

Figure 7 Cladding surface temperature (K) distribution in the single-rod channel
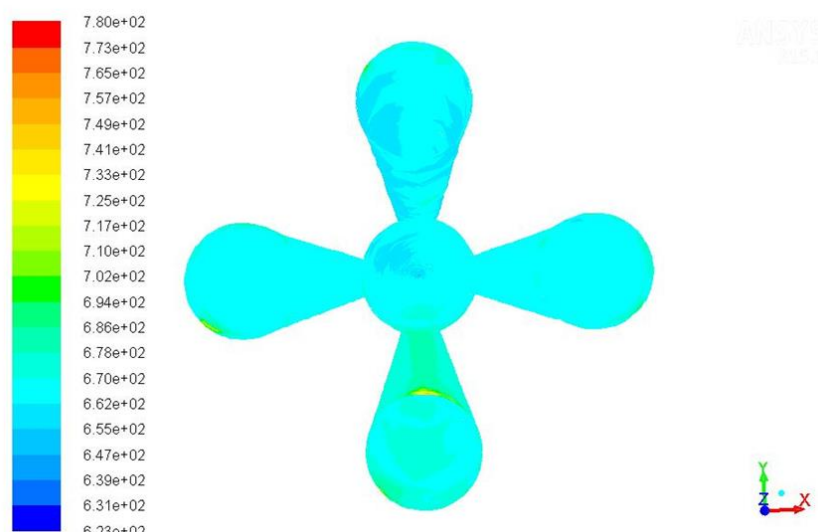

Figure 8 Cladding surface temperature $(\mathrm{K})$ distribution in the multi-rod channel

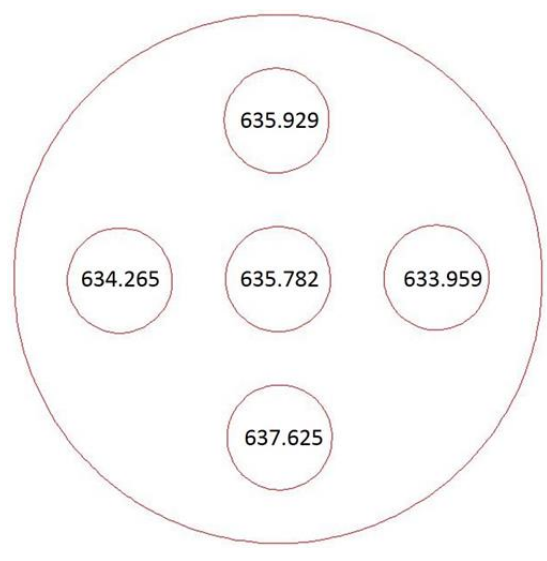

(a) Maximum temperature

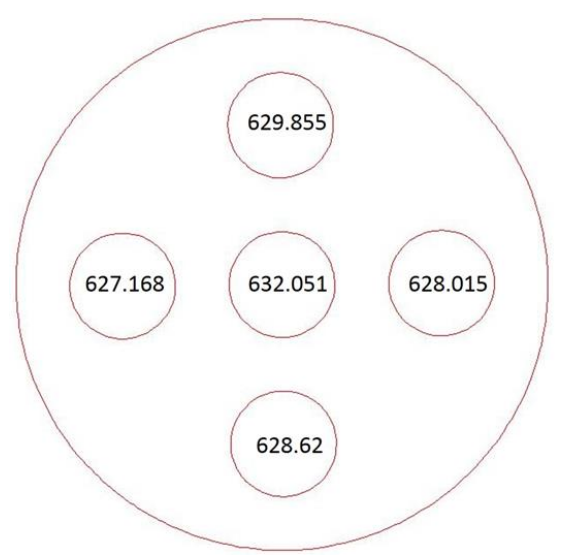

(b) Minimum temperature

Figure 9 Cladding surface temperatures $(\mathrm{K})$ at $\mathrm{z}=0.1 \mathrm{~m}$

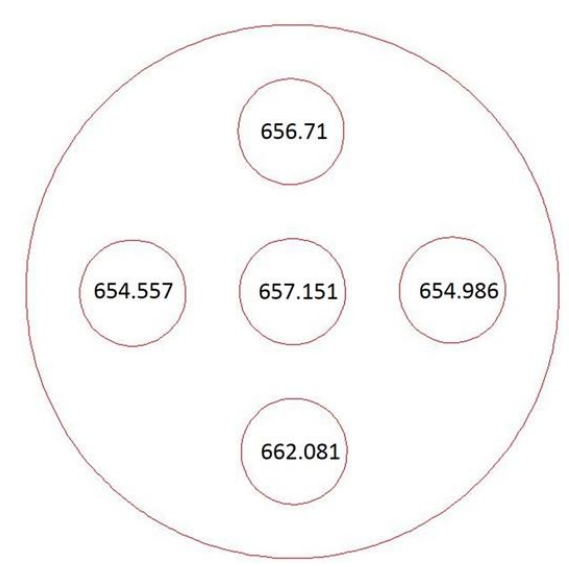

(a) Maximum temperature 


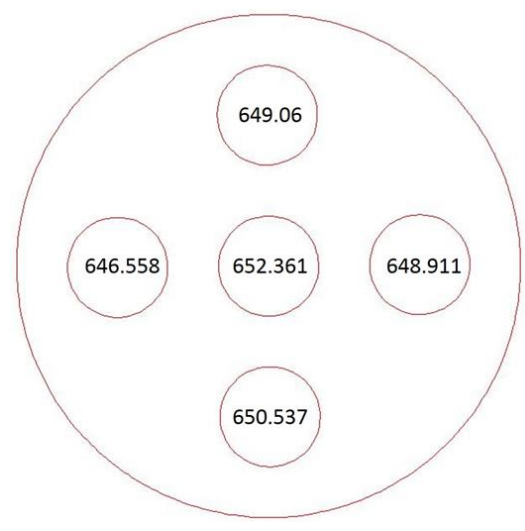

(b) Minimum temperature

Figure 10 Cladding surface temperatures $(K)$ at $\mathrm{z}=0.8 \mathrm{~m}$

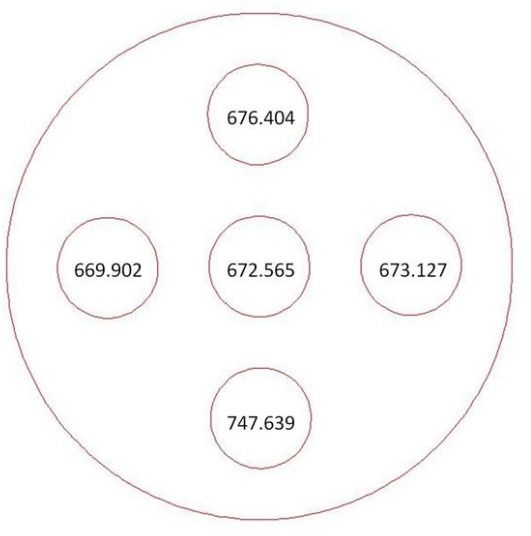

(a) Maximum temperature

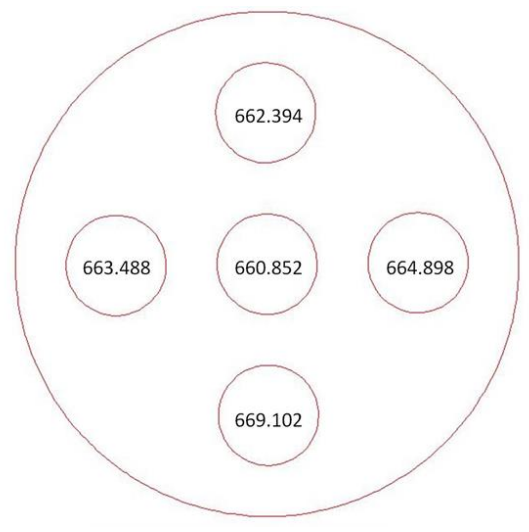

(b) Minimum temperature

Figure 11 Cladding surface temperatures $(\mathrm{K})$ at $\mathrm{z}=1.5 \mathrm{~m}$

\section{CONCLUSIONS}

In this study, the fluid flow and heat transfer characteristics of the supercritical water in the single-rod channel and the multi-rod channel are compared. The results show that there are secondary flows in the single-rod channel. The maximum cladding surface temperature in the multi-rod channel is about $110 \mathrm{~K}$ higher than that in the single-rod channel. Besides, the cladding surface temperature distributions are also not same between the single-rod channel and multi-rod channel. The difference of the circumference cladding surface temperature for the multi-rod channel can be up to $78.537 \mathrm{~K}$. The large circumferential temperature difference should be considered in the Canadian SCWR fuel bundle design. Since the heat transfer characteristics for the single rod channel and the multi-rod channel are not similar, the numerical simulations of the Canadian SCWR should be performed for the multi-rod channel in order to obtain more accurate results.

\section{REFERENCES}

[1] USNERAC, A Technology Roadmap for Generation IV Nuclear Energy Systems. Retrieved from The U.S.DOE nuclear energy research advisory committee and the generation IV international forum,2002.

[2] B. Kjellstrom, "Studies of turbulent flow parallel to a rod bundle of triangular array," Retrieved from AB Atomenergi,Sweden.vol.5, pp.190, May, 1974.

[3] A.C. Trupp and R.S. Azad, "The structure of turbulent flow in triangular array rod bundles," Nuclear Engineering and Design, vol.1, pp. 47-84, 1975.

[4] P. Carajilescov and N.E. Todreas, "Experimental and Analytical Study of Axial Turbulent Flows in an Interior Subchannel of a Bare Rod Bundle," Journal of Heat Transfer, vol.2, pp. 262-268, 1976.

[5] V. Vonka, "Measurement of secondary flow vortices in a rod bundle. Nuclear Engineering and Design," Nuclear Engineering and Design, vol.2, pp. 191-207, 1988

[6] H.Y. Jeong, K.S. Ha,Ha, Y.M. Kwon, Y.B. Lee, and D. Hahn, “A dominant geometrical parameter affecting the turbulent mixing rate in rod bundles," International Journal of Heat and Mass Transfer, vol.5, pp. 908-918,2007.

[7] X. Xi, Z. Xiao, X. Yan, Y. Li, and Y. Huang, "An experimental investigation of flow instability between two heated parallel channels with supercritical water," Nuclear Engineering and Design, pp. 171-181, 2014.

[8] S.K. Verma, S.L. Sinha, and D.K. Chandraker, "Experimental investigation of effect of spacer on single phase turbulent mixing rate on simulated subchannel of Advanced Heavy Water Reactor," Annals of Nuclear Energy, pp. 186-195,2017.

[9] H.Y. Gu, X. Cheng, and Y.H. Yang, "CFD analysis of thermalhydraulic behavior of supercritical water in sub-channels," Nuclear Engineering and Design, vol.2, pp. 364-374, 2010.

[10] T. Mukohara, S. Koshizuka, and Y.Oka, "Subchannel analysis of a fast reactor cooled by supercritical light water," Progress in Nuclear Energy, vol.1,pp. 197-204,2000.

[11] J.Y. Yu, S.T. Wang, and B.S. Jia, "Development of sub-channel analysis code for CANDU-SCWR," Progress in Nuclear Energy, vol.4, pp. 334350, 2007.

[12] X. Cheng, B. Kuang, and Y.H. Yang, "Numerical analysis of heat transfer in supercritical water cooled flow channels," Nuclear Engineering and Design, vol.3, pp. 240-252, 2007.

[13] Y.N. Zhang, C. Zhang, \& J.Jiang, "Numerical Simulation of Heat Transfer of Supercritical Fluids in Circular Tubes Using Different Turbulence Models. Journal of Nuclear Science and Technology, vol.3, pp. 366-373, 2011.

[14] P.W. Sun, "Dynamic Model Construction and Control System Design for Canadian Supercritical Water-cooled Reactors," Doctor of Philosophy, The University of Western Ontario, Electronic Thesis and Dissertation Repository,2012.

[15] Ansys Fluent. Fluent 14.0 User's Guide,2011.

[16] W.Wagner and A.Kruse, Properties of Water and Steam. New York: Springer, 1998.

[17] L.Leung, "Overview of SCWR Concepts”, 2013. 